\title{
Oral and maxillofacial surgery: should a district service be retained?
}

\author{
G. D. WOOD \& S. HERION
}

Department of Oral and Maxillofacial Surgery, Arrowe Park Hospital, Upton, Wirral, Merseyside

\section{SUMMARY}

The adult new patient attendances at a District General Hospital for 1988 and 1989 have been analysed and the patients with oral and maxillofacial injuries identified. The injuries were classified using the International Classification of Diseases. The time spent undertaking emergency surgery out of hours by each firm using the operating facility has been analysed. An argument for a national district service in Oral and Maxillofacial Surgery is developed and advanced drawing on the results obtained from the study.

\section{INTRODUCTION}

Arrowe Park Hospital, one of the five pilot sites for the resource management initiative and recently also named as a site where the new funding arrangements (GP budgets) will be tested (each patient treated brings an income to the hospital), serves a local population of approximately 350000 . This and other hospitals stimulated by the White Paper 'Working for Patients' (1989) and the resource management initiative are reviewing their medical practice and delivery of treatment to patients. One area, the problem of supplying 24-h a day emergency services, within the constraints of compulsory rotas not more onerous than one night in three on duty for trainees, coupled with no funding for additional staff to enable compliance with these rotas, is resulting in a critical appraisal of the need and demand for a variety of services at Arrowe Park and every District General Hospital. The Mersey Region has seven Consultant Oral and Maxillofacial Surgeons working in its districts, while the teaching centre (Liverpool Dental Hospital) has no Professor or Senior Lecturer in the specialty. A wide range of minor and major oral and maxillofacial surgery is undertaken in the Mersey districts, which is

Correspondence: Geoffrey D. Wood, Department of Oral and Maxillofacial Surgery, Arrowe Park Hospital, Arrowe Park Road, Upton, Wirral, Merseyside L49 SPE 
common throughout the United Kingdom. The Central Committee for Hospital Dental Services recommends that no withdrawal from District General Hospitals to Regional Centres should occur in maxillofacial surgery. A study has, therefore, been undertaken to evaluate the work of the district Department of Oral and Maxillofacial Surgery in the Accident and Emergency Unit of Arrowe Park Hospital. The number of hours spent in emergency operating theatres by each specialty have also been calculated and a comparison made to determine relative usage of the theatres outside 'normal' hours.

\section{MATERIALS AND METHODS}

The records of all the new adult patient attendances during alternate months at the Accident and Emergency Unit in 1988 and 1989 were examined and those relating to oral and maxillofacial injuries identified. The latter were coded according to the Ninth Revision of the International Classification of Diseases, Injuries and Causes of Death (ICD 9, 1977) and the date and time of presentation of each case were detailed.

The computerized operating theatre records from 1st April, 1988 - 31st March, 1989 were examined and the number of hours spent operating on emergency cases 'out of hours' by each surgical firm identified and recorded. The percentage ratios of hours of emergency to elective surgery during that period were calculated for each surgical firm and compared.

\section{RESULTS}

The numbers of patients with oral and maxillofacial injuries presenting to the A\&E Unit each day of the alternate months investigated were similar. No significant difference was detected using the analysis of variance with respect to the total number presenting for treatment (Figs $1 \& 2$ ).

Patients presented throughout the 24 -h periods and as many patients attended in social (9 a.m. to 5 p.m.) as in unsocial hours (Figs 1 \& 2).

The ICD 9 coding demonstrated that patients seen by members of the Department of Oral and Maxillofacial Surgery formed three distinct groups: (1) Dental (525); (2) Contusions (920) and; (3) Lacerations (870, 872, 873, 874). The number of cases in these groups (for the alternate months of the years investigated) is shown in Table 1.

The comparison, by specialty, of the emergency operating hours allocated, is shown in Table 2.

\section{DISCUSSION}

Arrowe Park Hospital is the principal hospital providing $24 \mathrm{~h}$ a day emergency 
Fig. 1. Months of 1988
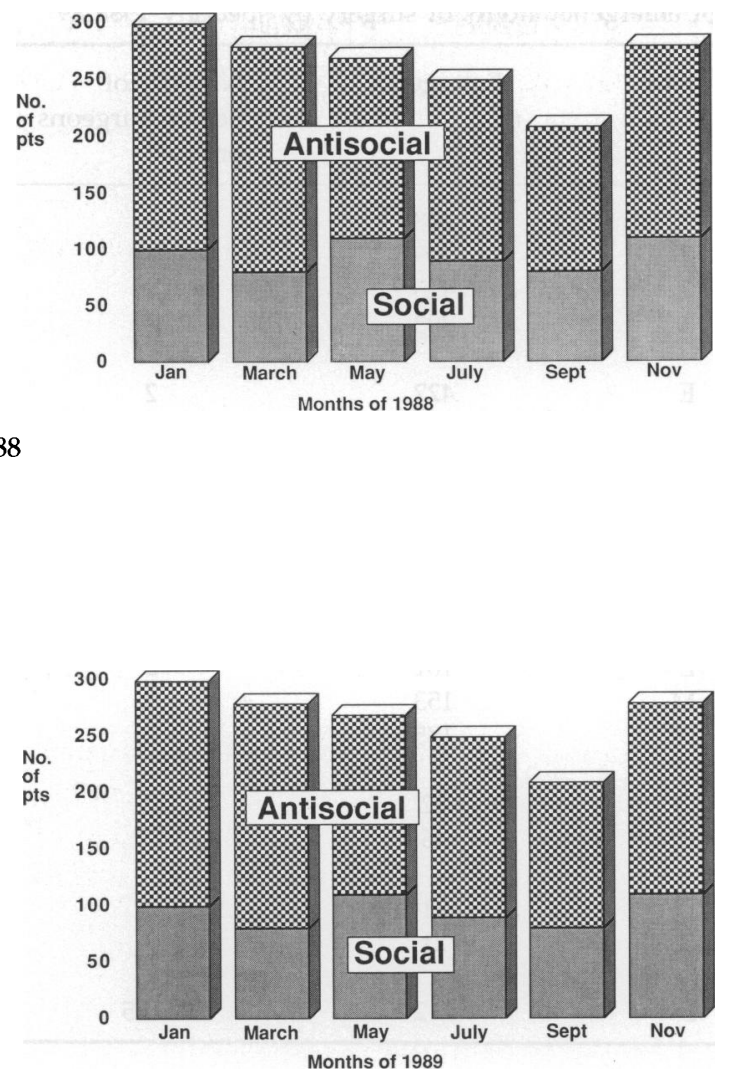

Fig. 2. Months of 1989

Table 1. The oral and maxillofacial patients in alternate months of 1988 and 1989 classed by the International Classification of Diseases (ICD 9)

\begin{tabular}{llrr}
\hline ICD 9 & Site of injury & \multicolumn{2}{c}{ Totals } \\
& & 1988 & 1989 \\
\hline 920 & Contusion-face & 664 & 556 \\
921 & Contusion-eye & 8 & 9 \\
525 & Teeth & 107 & 114 \\
870 & Laceration-eye & 59 & 46 \\
874 & Laceration-neck & 5 & 0 \\
872 & Laceration-ear & 21 & 20 \\
873 & Laceration-head & 737 & 717 \\
\hline
\end{tabular}

Facial fractures are included in 920 and 921 
Table 2. Comparison of emergency hours of surgery by specialty 1988/89

\begin{tabular}{|c|c|c|c|c|}
\hline Specialty & Firm & Emergency & $\begin{array}{l}\text { Number of } \\
\text { Senior Surgeons } \\
\text { on call* }\end{array}$ & $\begin{array}{l}\text { Total Surgeons } \\
\text { including Clinical } \\
\text { Assistants }\end{array}$ \\
\hline \multirow[t]{4}{*}{ General Surgery } & A & 408 & 2 & \\
\hline & B & 409 & 1 & 14 \\
\hline & $\mathrm{C}$ & 415 & 2 & \\
\hline & $\mathrm{D}$ & 303 & 2 & \\
\hline \multirow{5}{*}{ Orthopaedic } & E & 422 & 2 & \\
\hline & $\mathrm{F}$ & 384 & 2 & 21 \\
\hline & G & 405 & 2 & \\
\hline & $\mathrm{H}$ & 467 & 2 & \\
\hline & I & 386 & 2 & \\
\hline \multirow[t]{5}{*}{ Gynaecology } & $\mathrm{J}$ & 91 & 2 & \\
\hline & $\mathrm{K}$ & 114 & 2 & \\
\hline & L & 161 & 2 & 23 \\
\hline & M & 153 & 2 & \\
\hline & $\mathrm{N}$ & 185 & 2 & \\
\hline \multirow[t]{2}{*}{ Ophthalomology } & $\mathrm{O}$ & 22 & 2 & 9 \\
\hline & $\mathbf{P}$ & 46 & 2 & \\
\hline \multirow[t]{2}{*}{ ENT } & $\mathrm{Q}$ & 21 & 2 & 5 \\
\hline & $\hat{\mathbf{R}}$ & 21 & 2 & \\
\hline Oral Surgery & $\mathrm{S}$ & 212 & 0.5 & 3 \\
\hline
\end{tabular}

* Those graded Registrar or Senior

services on the Wirral Peninsula. Patients of all social classes from both urban and rural areas attend for treatment. One area of the peninsula has been cited as cne of the most troublesome in the country for drug addiction, yet other areas contain some of the most affluent housing in the North West of the U.K. The casualties that present to the A\&E Unit are comparable with those attending other A\&E departments serving a similar population and the results of this study may, therefore, be considered to be typical of a national pattern.

Nearly $6 \%$ of the annual total of new attendances at the Arrowe Park A\&E Unit have oral and maxillofacial injuries. This figure represents approximately 3000 adult patients. Most of these are treated as out-patients in the A\&E Unit under a local anaesthetic and those patients requiring a follow-up examination are seen in the Department of Oral \& Maxillofacial Surgery. Child (under the age of 14) injuries have not been analysed. Patients requiring in-patient treatment are hospitalized and any surgery is carried out in the operating theatre. These facts would suggest that not only Arrowe Park but most other District General Hospitals should be served by teams of oral and maxillofacial surgeons. These teams obviously require some members 'on-site', rather than 'on-call' from other hospitals, 
because of both the number and distribution of causalties over a 24-h period. It is, therefore, apparent that Oral \& Maxillofacial Surgery should be considered one of the 'core-specialties' described in 'Working for Patients'.

If oral and maxillofacial surgical expertise were to be concentrated at so called 'Regional Centres', it is unlikely that all casualties requiring specialized treatment would, or could, be transferred from the District General Hospitals to these centres. It is possible that peripatetic Oral \& Maxillofacial Surgeons based at the 'Regional Centres' might attend District General Hospitals, subject to other commitments, but it is more likely that other surgical disciplines within the District General Hospital would take on the work, both as a pragmatic move and as a consequence of the new hospital funding arrangements. The most likely net effect of withdrawal of existing oral and maxillofacial services from the District General Hospitals would be a significant reduction in the quality of care available to large numbers of patients.

The current practice, whereby all casualties are initially assessed by a casualty officer and then referred for appropriate specialist treatment, results in delayed treatment for all. As most patients with oral and maxillofacial injuries have no other injuries (Rowe \& Williams, 1985) a different method of delivery of this care is currently being investigated. Oral and Maxillofacial Surgery Department staff initially see self-categorized patients in the A\&E Unit and refer those cases requiring other expertise.

Should this system prove to be satisfactory then $6 \%$ of A\&E medical staff time should thereby be saved. This time saving could then either by transferred to other A\&E Department work or used to fund staffing for the compulsory one night on duty in three rotas for oral and maxillofacial surgery trainees.

Trainee oral and maxillofacial surgeons gain considerable experience during treatment of emergency cases. More staff are, however, required in the specialty and funding for posts should be provided to enable one night in three on duty rotas and a District service to be either established or continued.

Dental injuries (ICD 9 code 525) represent about $7 \%$ of all oral and maxillofacial injuries. If Oral and Maxillofacial Surgery services are withdrawn to Regional Centres the new contract for General Dental Practitioners may mean that some of these patients will be treated in the general dental service. However, a District General Hospital will still need the services of a dental surgeon to treat those patients admitted to hospital with injuries to the teeth and jaws in addition to other injuries. Patients with dental injuries presenting to A\&E and those patients who present with oral and dental problems whilst being treated for unrelated conditions, will also still require treatment. This treatment, some of which must be carried out on patients confined to bed, is at present undertaken by Oral \& Maxillofacial Surgery Department staff. It is possible that some of this treatment could be carried out by 'visiting' dental surgeons but, just as in the A\&E situation, it is likely that there would be a significant reduction in the quality and quantity of care.

The use of the operating theatres for treatment of the more severe injuries under general anaesthesia by the Department of Oral and Maxillofacial Surgery is high (Table 2). The number of staff available to undertake the workload is low (Wood, 
1990). The Oral and Maxillofacial Surgery Department still requires a $40 \%$ addition $\frac{\vec{\Phi}}{\Theta}$ to its allocated routine operating time to treat severe injuries and a case for an 3 increase in the staffing has already been made (Wood, 1990). The additional $\stackrel{\circ}{\circ}$ surgical time is at present obtained during unsociable hours. Facilities and staff $\vec{\Rightarrow}$ are required if the work is to be undertaken during sociable hours and arguably $\frac{0}{\circ}$ the patients may be better treated by surgeons who are refreshed sufficiently to $\frac{0}{\circ}$ undertake it, rather than by those working on after the end of busy clinics or $\frac{\overline{\bar{m}}}{\overrightarrow{\mathrm{m}}}$ operating lists.

The specialty of Oral and Maxillofacial Surgery has evolved to become an essential part of the District General Hospital. The specialty must now remain on $\overrightarrow{0}$ site and be supplemented there, otherwise much of the emergency treatment it now provides will be of poorer quality, and some emergency treatment will have $\vec{\omega}$ to be carried out by non-specialists.

\section{ACKNOWLEDGEMENTS}

We thank Professor Mike Edgar, Professor of Dental Science at Liverpool Dental Hospital, and Mr John Hutton, Consultant Radiologist at Liverpool Dental Hospital, for their assistance with the statistical analysis and for encouragement.

\section{REFERENCES}

Rowe, N. L. \& Williams, J. L. (1985) Maxillofacial Injuries. Vol. I p. 37. Churchill Livingstone, Edinburgh Wood, G. D. (1990) Hours of Surgery. British Dental Journal, 168 (8) 110.

Working for Patients (1989) Papers 1-8, Her Majesty's Stationery Office, London.

World Health Organization (1977) Manual of the International Statistical Classiciation of Diseases, Injuries and Causes of Death, Ninth Revision. Vol. I 301-309, 493-494, 507, WHO, Geneva. 